\title{
The effect of the age of the serpentine leafminer Liriomyza trifolii (Diptera: Agromyzidae) on parasitism by the parasitoid wasp Gronotoma micromorpha (Hymenoptera: Figitidae: Eucoilinae)
}

\author{
YoshinISA ABE \\ Biosystematics Laboratory, Graduate School of Social and Cultural Studies, Kyushu University, 744 Motooka, \\ Nishi-ku, Fukuoka 819-0395, Japan; e-mail: y_abe@scs.kyushu-u.ac.jp
}

Key words. Host suitability, host acceptance, ovipositional preference, host feeding, host stinging

\begin{abstract}
Gronotoma micromorpha is a solitary egg-pupal and larval-pupal parasitoid. In a previous study, the developmental time of this parasitoid decreased with the age of its leaf miner host, Liriomyza trifolii, being significantly longer when the host was 0-day old (= $0-24 \mathrm{~h}$ old egg) than when 4 days old (mature larva) at the time of parasitization at $25^{\circ} \mathrm{C}$. In the present study, the suitability and acceptability of 0 and 4 day old L. trifolii as hosts for G. micromorpha, and the ovipositional preference of this parasitoid for these two developmental stages of the host were examined. No significant difference was found in the size of the parasitoid offspring that emerged from hosts parasitized at these two developmental stages. There was no significant difference in the acceptability of the two developmental stages of $L$. trifolii in no choice tests, but 4 day old larvae were preferred to 0 day old eggs in choice tests. Moreover, parasitization of eggs by G. micromorpha did not appear to result in more of the eggs dying before they hatched. Nonreproductive killing (host feeding and host stinging without oviposition) of host eggs by this parasitoid was also not detected.
\end{abstract}

\section{INTRODUCTION}

A female parasitoid can influence the fitness of her offspring by her choice of a host, since the quality of the host can affect offspring fitness (Luck \& Nunney, 1999). Since parasitoid females appear to select hosts according to the effect they have on their offspring's fitness, the ovipositional preference of the parasitoid is thought to be correlated with the suitability of hosts for juvenile parasitoid development (Hopper \& King, 1984; Brodeur et al., 1998; Neveu et al., 2000). Host suitability is an important determinant of successful parasitism by parasitoids (Doutt, 1959; Vinson \& Iwantsch, 1980) and the age of a host influences its suitability (Vinson, 1976; Godfray, 1994). Vinson (1998) pointed out that, compared to idiobionts, koinobionts attack a wider variety of host ages, because after oviposition the hosts are able to grow sufficiently to provide for the parasitoids' development. However, even in koinobionts the age of the host influences host suitability (Godfray, 1994). The relationship between parasitoid fitness and the age or size of its host is described for some koinobiont parasitoid species (e.g., Nicol \& Mackauer, 1999; Harvey et al., 2000; Chau \& Mackauer, 2001; Colinet et al., 2005).

Larval-pupal parasitism occurs in the subfamily Eucoilinae (Figitidae) and egg-pupal parasitism in Gronotoma micromorpha (Perkins) (Abe, 2001). Egg-pupal parasitism is restricted to some species of Braconidae and a few species of Ichneumonidae (Gauld \& Bolton, 1988; Quicke, 1997). To my knowledge G. micromorpha is the only hymenopterous parasitoid with both modes of parasitism (Abe, 2001). The serpentine leafminer, Liriomyza trifolii (Burgess), develops from egg to mature larva in 4 days, and the age of the host at the onset of parasitism does not significantly influence the percentage of $G$. micromorpha offspring that survive to the adult stage. However, the developmental time of the parasitoid decreases with increase in host age, and is more than 1.5 days shorter when $L$. trifolii are parasitized when 3 to 4 days old compared to 0 day old at $25^{\circ} \mathrm{C}$ (Abe, 2001). Five different relationships between parasitoid development time and host age at the commencement of parasitism are recognized, and the negative relationship reported for $G$. micromorpha parasitizing $L$. trifolii occurs in some other parasitoids (Colinet et al., 2005). In another eucoilid, Trybliographa rapae, which can successfully parasitize all larval stages of its host, the first instar larvae of the parasitoid remain at this stage until the host pupates (Wishart \& Monteith, 1954). The longer developmental time of G. micromorpha when it parasitizes the eggs of its host may be due to prolongation of the time spent in the first instar larva as in T. rapae. Although body size and developmental time (or development rate) are considered to be primary indicators of fitness in parasitoids (Roitberg et al., 2001), the latter may not be as good as an indicator as the former in G. micromorpha.

Gronotoma micromorpha is a solitary parasitoid, which reproduces thelytokously because it is infected with $\mathrm{Wol}$ bachia (Arakaki et al., 2001). This parasitoid occurs in subtropical regions, i.e., Okinawa, Indonesia, Florida, Hawaii, Guam and Tahiti (Yoshimoto, 1963; Beardsley, 1988; Rauf et al., 2000; Abe \& Konishi, 2004). On Okinawa and Guam, G. micromorpha appears to be the dominant parasitoid of L. trifolii (Johnson, 1993; Konishi, 1998) and in Indonesia is an important parasitoid of the pea leafminer L. huidobrensis (Blanchard) (Rauf et al., 2000; Prijono et al., 2004). Under laboratory conditions, 
G. micromorpha has a high net reproductive rate when it parasitizes L. trifolii (Abe \& Tahara, 2003) and the tomato leafminer L. bryoniae (Kaltenbach) is also a suitable host for this parasitoid (Abe, 2006). Thus, G. micromorpha may be a useful biological control agent of some pest species of Liriomyza.

A previous study (Abe, 2001) indicates that a mature larva of $L$. trifolii is more suitable than an egg as a host for G. micromorpha, based on the developmental time of the parasitoid's offspring. The present study compared the size of $G$. micromorpha offspring emerging from $L$. trifolii parasitized at the egg and mature larval stages, because body size is another important index of parasitoid fitness. To examine egg-pupal and larval-pupal parasitism in G. micromorpha in more detail, host acceptance (in nochoice tests) and ovipositional preference (in choice tests) of this parasitoid were assessed in the laboratory. The tiny and fragile eggs of the host are susceptible to injuries caused by oviposition, host feeding and host stinging without oviposition. Thus, the survival to hatching of eggs exposed to parasitism was determined.

\section{MATERIAL AND METHODS}

\section{General methods}

All insects were maintained and experiments conducted at $25^{\circ} \mathrm{C}$ under a 15L: 9D photoperiod. A laboratory culture of $G$. micromorpha was established using adults that emerged from leafminer infested kidney bean, Phaseolus vulgaris L., leaves collected at Itoman, Okinawa Prefecture, in April 1998. The culture of the parasitoid was maintained on L. trifolii larvae. A laboratory culture of L. trifolii was established using larvae collected at Itoman in April 1998. Phaseolus vulgaris was used as the host plant for maintaining the leafminer colony and for experiments (for rearing details, see Abe, 2001).

The base of the stem of one or two host plants infested with 0 day old ( $0-24 \mathrm{~h}$ old) or 4 day old $L$. trifolii was immersed in water in a $10-\mathrm{ml}$ glass vial placed inside and at the bottom of a cylindrical glass tube $(6.4 \mathrm{~cm}$ diameter, $22 \mathrm{~cm}$ high). The top of the glass tube was covered with organdy and the bottom with Kim-wipe ${ }^{\circledR}$. Undiluted honey was streaked on the inside of the glass tube as a source of food for the wasps. Immediately after, one naive (0-24 h old, no oviposition experience) female $G$. micromorpha was released into the tube and allowed to parasitize the host insects for $24 \mathrm{~h}$. Preliminary observations (Abe, 2001) indicate that the eggs of $L$. trifolii hatch after approximately $48 \mathrm{~h}$ and the larvae take 2 to 3 days to mature.

\section{Emergent parasitoid body size and host age}

To compare the suitability of 0 and 4 day old L. trifolii as hosts the sizes of the parasitoids that developed in these hosts were determined. One G. micromorpha female was provided with more than 40 either 0 or 4 day old $L$. trifolii on a host plant. These hosts were reared until wasps emerged. Each host stage trial was replicated 20 times. The hind tibial length of one wasp, randomly selected from each replicate, was measured under a binocular stereomicroscope using an ocular micrometer.

\section{Host acceptance}

To compare the host acceptance of 0 and 4 day old L. trifolii by $G$. micromorpha, each female parasitoid was provided with either sufficient ( 40 and above) 0 or 4 day old hosts infesting the first two true leaves of a host plant. The mean $( \pm \mathrm{SE})$ numbers of 0 and 4 day old hosts were similar, $57.0 \pm 2.7$ and $54.5 \pm 2.8$, respectively (two-tailed Student's t-test, $\mathrm{t}=-0.643$, d.f. $=38$,
$P>0.05)$. There were a total of 20 trials for each host stage. The 0 day old hosts were reared for three days after removal of the wasp from the tube. They were then transferred from the leaves into Ringer's solution and dissected with minute pins under a binocular stereomicroscope to determine whether they were parasitized. The 4 day old hosts were transferred from the leaves into Ringer's solution and dissected shortly after removal of the wasp from the tube.

\section{Ovipositional preference}

To assess whether G. micromorpha preferred to oviposit in 0 or 4 day old $L$. trifolii, each female parasitoid was provided with 0 day old $L$. trifolii on a leaf of one host plant and 4 day old $L$. trifolii on a leaf of another host plant. The parasitism of these $L$. trifolii hosts by G. micromorpha was determined as in the host acceptance experiment. There were 20 replicates of each host stage.

\section{Data analysis}

A two-tailed Student's t-test was used to detect differences in the hind tibial length of G. micromorpha offspring that emerged from the two host groups. The influence of the age of the host on the percentage parasitized by G. micromorpha was analyzed using two-tailed Student's t-tests after arcsine transformation of the data. Ovipositional preference of G. micromorpha was analyzed by paired two-tailed Student's t-test after weighting data for proportional availability of hosts, as there were different numbers of hosts available to the parasitoids (eggs: 18-44, mature larvae: 12-30). The weighting was done as follows: the number of $L$. trifolii eggs parasitized was divided by eggs / (eggs + mature larvae); the number of L. trifolii mature larvae parasitized was divided by mature larvae / (eggs + mature larvae). The significance level for all statistical tests was set at $\mathrm{P}$ $=0.05$.

\section{RESULTS \\ Effect of host age on the body size of the adult parasitoid}

There was no significant difference between the mean ( $\pm \mathrm{SE}$ ) hind tibial length of the G. micromorpha offspring from hosts parasitized when $0(0.399 \pm 0.005 \mathrm{~mm})$ and 4 days old $(0.387 \pm 0.007 \mathrm{~mm})$ (two-tailed Student's t-test, $\mathrm{t}=-1.387$, d.f. $=38, \mathrm{P}>0.05)$.

\section{Host acceptance}

The mean ( $\pm 95 \%$ confidence interval) percentages of 0 and 4 day old $L$. trifolii parasitized by $G$. micromorpha were $42.6 \pm 7.1$ and $45.2 \pm 6.1 \%$, respectively. There was no significant difference in the percentage parasitism of these two host stages of L. trifolii (two-tailed Student's t-test, $\mathrm{t}=-0.532$, d.f. $=38, \mathrm{P}>0.05)$.

\section{Ovipositional preference}

The mean $( \pm \mathrm{SE})$ weighted numbers of the 0 and 4 day old L. trifolii parasitized by G. micromorpha were $18.9 \pm$ 1.8 and $27.5 \pm 2.2$, respectively. The latter host stage was parasitized significantly more than the former (paired two-tailed Student's t-test, $\mathrm{t}=-2.507$, d.f. $=19, \mathrm{P}=0.02$ ).

\section{Host egg-mortality}

In the host acceptance experiment, a total of 105 dead eggs and 16 dead first instar larvae of $L$. trifolii were found after rearing 1,139 0 day old $L$. trifolii previously exposed to G. micromorpha. The 105 dead host eggs con- 
tained no G. micromorpha eggs or larvae, but 2 of the 16 dead first instar host larvae contained parasitoid eggs. Of the 1,139 0 day old L. trifolii, 472 were parasitized. Thus, the percentage of the parasitized $L$. trifolii eggs that hatched was $100 \%$, and it was inferred that $84.3 \%$ of those that were not parasitized hatched. In the ovipositional preference experiment, a total of 62 dead eggs and 6 dead first instar larvae of $L$. trifolii were found after rearing 5680 day old $L$. trifolii previously exposed to $G$. micromorpha. Two of the 62 dead L. trifolii eggs contained parasitoid eggs, but the 6 dead first instar larvae did not. Of the 5680 day old L. trifolii 209 were parasitized. Thus, the percentage of parasitized L. trifolii eggs that hatched was inferred to be $99 \%$, and that of unparasitized eggs $83.3 \%$.

\section{DISCUSSION}

No significant difference was detected in the hind tibial length of female G. micromorpha that resulted from eggpupal and larval-pupal parasitism. Large female parasitoids are generally more fecund than small ones (Hurlbutt, 1987; King, 1987; Rosenheim \& Rosen, 1991; Visser, 1994; Vet et al., 1994; Kazmer \& Luck, 1995; West et al., 1996; Bennett \& Hoffmann, 1998; Ellers et al., 1998; Luck \& Nunney, 1999; Harvey et al., 2000). Thus, the present results indicate that eggs and mature larvae of $L$. trifolii are equally suitable hosts for the development of the offspring of this parasitoid. However, these results are not consistent with a previous study (Abe, 2001), which showed that the developmental time of this parasitoid was significantly shorter when $L$. trifolii was parasitized at the mature larval stage compared to the egg stage, indicating that the mature larva is a more suitable host than the egg (Abe, 2001). In many cases, the developmental time of koinobiont parasitoid offspring decreases when the host is parasitized at a later developmental stage (e.g., Neveu et al., 2000). As shown in $T$. rapae by Wishart \& Monteith (1954), G. micromorpha probably delays its development when it parasitizes host eggs in order to allow the host to grow larger and thus provide more resources. Therefore, developmental time may not be a good means of evaluating fitness in $G$. micromorpha. The age of $L$. trifolii at the time of oviposition did not significantly influence the percentage emergence of G. micromorpha adults from L. trifolii (Abe, 2001). Percentage emergence is a combination of host acceptability and offspring survival. In the present study, there was no significant difference in the acceptability of eggs and mature larvae of $L$. trifolii in the no-choice tests. Hence, the offspring survival of $G$. micromorpha is independent of whether it oviposits in eggs or mature larvae of L. trifolii. Body size and developmental time are the primary traits used to evaluate fitness of parasitoids, and offspring survival is a secondary trait (Roitberg et al., 2001). These biological traits are affected by the host instar parasitized (Hopper \& King, 1984). In G. micromorpha, however, the relationships between developmental time, the other two traits and fitness differ. Thus, it is better to use more than one trait when evaluating parasitoid fitness.

It is predicted that foraging female parasitoids that encounter hosts of different stages should select the most suitable. In terms of developmental time (development rate), mature larvae of $L$. trifolii are more suitable than eggs for G. micromorpha (Abe, 2001), although in terms of offspring body size or survival (present study) they are equally suitable. G. micromorpha exhibited a significant preference for mature larvae of $L$. trifolii. Compared to larvae, the eggs of $L$. trifolii are motionless, small and concealed in leaf tissue. Thus, it may be more difficult for a parasitoid to recognize and subsequently utilize eggs than larvae. This may account for why this parasitoid prefers to oviposit in larvae rather than the eggs of its host.

Egg-pupal parasitism is a rare case among parasitoids (Gauld \& Bolton, 1988; Quicke, 1997), presumably because it is difficult for an immature parasitoid to survive the many host stage changes from egg to pupa. As mentioned above, the eggs of L. trifolii are less conspicuous than the larvae. The difficulty of locating eggs may be an additional constraint on the evolution of eggpupal parasitism in hymenopterous parasitoids.

Almost all of the L. trifolii eggs that were parasitized by G. micromorpha hatched. As in other egg-pupal parasitoids (Clausen, 1954; Quicke, 1997), it is thought that $G$. micromorpha oviposits in host eggs that are at an advanced stage of development. In a previous study, $82.5 \%$ of the eggs of L. trifolii that had not been exposed to parasitoids hatched under the same conditions as used in the present study (Tokumaru \& Abe, 2003). The percentage of unexposed and exposed eggs of L. trifolii that hatched appears to be almost the same. Therefore, the eggs of L. trifolii that are parasitized by G. micromorpha are not less likely to hatch. Non-reproductive killing of host eggs by this parasitoid was not detected. Embryonic development probably did not occur in those eggs of $L$. trifolii that did not hatch, and G. micromorpha females may not oviposit in such eggs. Further study is needed to determine how G. micromorpha females detect whether the eggs of L. trifolii are viable.

ACKNOWLEDGEMENT. I would like to thank Y. Yoshiyasu, Laboratory of Applied Entomology, Graduate School of Agriculture, Kyoto Prefectural University, for his suggestions.

\section{REFERENCES}

ABE Y. 2001: Egg-pupal and larval-pupal parasitism in the parasitoid Gronotoma micromorpha (Hymenoptera: Eucoilidae). Appl. Entomol. Zool. 36: 479-482.

ABE Y. 2006: Exploitation of the serpentine leafminer Liriomyza trifolii and tomato leafminer L. bryoniae (Diptera: Agromyzidae) by the parasitoid Gronotoma micromorpha (Hymenoptera: Eucoilidae). Eur. J. Entomol. 103: 55-59.

AbE Y. \& Konishi K. 2004: Taxonomic notes on Gronotoma (Hymenoptera: Eucoilidae) parasitic on the serpentine leafminer, Liriomyza trifolii (Diptera: Agromyzidae). Esakia 44: 103-110.

Abe Y. \& TAhara M. 2003: Daily progeny production and thermal influence on development and adult longevity of the 
leafminer parasitoid, Gronotoma micromorpha (Hym., Eucoilidae). J. Appl. Entomol. 127: 477-480.

Arakaki N., Oishi T. \& Noda H. 2001: Parthenogenesis induced by Wolbachia in Gronotoma micromorpha (Hymenoptera: Eucoilidae). Entomol. Sci. 4: 9-15.

BeARDSLEY JR. J.W. 1988: Eucoilid parasites of agromyzid leafminers in Hawaii (Hymenoptera: Cynipoidea). Proc. Hawaii. Entomol. Soc. 28: 33-47.

Bennett D.M. \& Hoffmann A.A. 1998: Effects of size and fluctuating asymmetry on field fitness of the parasitoid Trichogramma carverae (Hymneoptera: Trichogrammatidae). $J$. Anim. Ecol. 67: 580-591.

Brodeur J., Geervliet J.B.F. \& Vet L.E.M. 1998: Effects of Pieris host species on life history parameters in a solitary specialist and gregarious generalist parasitoid (Cotesia species). Entomol. Exp. Appl. 86: 145-152.

Chau A. \& Mackauer M. 2001: Host-instar selection in the aphid parasitoid Monoctonus paulensis (Hymenoptera: Braconidae, Aphidiinae): assessing costs and benefits. Can. Entomol. 133: 549-564.

Clausen C.P. 1954: The egg-larval host relationship among the parasitic Hymenoptera. Boll. Lab. Zool. Gen. Agr. Portici. 33 . 119-133.

Colinet H., Salin C., Boivin G. \& Hance T.H. 2005: Host age and fitness-related traits in a koinobiont aphid parasitoid. Ecol. Entomol. 30: 473-479.

Doutt R.L. 1959: The biology of parasitic Hymenoptera. Annu. Rev. Entomol. 4: 161-182.

Ellers J., van Alphen J.J.M. \& Sevenster J.G. 1998: A field study of size-fitness relationships in the parasitoid Asobara tabida. J. Anim. Ecol. 67: 318-324.

Gauld I. \& Bolton B. 1988: The Hymenoptera. Oxford Univ. Press, Oxford, $332 \mathrm{pp}$.

Godfray H.C.J. 1994: Parasitoids. Princeton Univ. Press, Princeton, $473 \mathrm{pp}$.

Harvey J.A., Kadash K. \& Strand M.R. 2000: Differences in larval feeding behavior correlate with altered developmental strategies in two parasitic wasps: implications for the sizefitness hypothesis. Oikos 88: 621-629.

Hopper K.R. \& KING E.G. 1984: Preference of Microplitis croceipes (Hymenoptera: Braconidae) for instars and species of Heliothis (Lepidoptera: Noctuidae). Environ. Entomol. 13: $1145-1150$

HuRLbutt B. 1987: Sexual size dimorphism in parasitoid wasps. Biol. J. Linn. Soc. 30: 63-89.

Johnson M.W. 1993: Biological control of Liriomyza leafminers in the Pacific Basin. Micronesica (Suppl.) 4: 81-92.

KAZMER D.J. \& LUCK R.F. 1995: Field tests of the size-fitness hypothesis in the egg parasitoid Trichogramma pretiosum. Ecology 76: 412-425.

KING B.H. 1987: Offspring sex ratios in parasitoid wasps. Quart. Rev. Biol. 62: 367-396.

Konishi K. 1998: An illustrated key to the hymenopterous parasitoids of Liriomyza trifolii in Japan. Misc. Pub. Nat. Inst. Agro-Environ. Sci. 22: 27-76.

LuCK R.F. \& NunNEY L. 1999: A Darwinian view of host selection and its practical implications. In Hawkins A. \& Cornell
H.V. (eds): Theoretical Approaches to Biological Control. Cambridge University Press, Cambridge, UK, pp. 283-303.

Neveu N., Krespi L., Kacem N. \& Nenon J.-P. 2000: Host-stage selection by Trybliographa rapae, a parasitoid of the cabbage root fly Delia radicum. Entomol. Exp. Appl. 96: 231-237.

Nicol C.M.Y. \& Mackauer M. 1999: The scaling of body size and mass in a host-parasitoid association: influence of host species and stage. Entomol. Exp. Appl. 90: 83-92.

Prijono D., Robinson M., Rauf A., Buorksten T. \& Hoffmann A.A. 2004: Toxicity of chemicals commonly used in Indonesian vegetable crops to Liriomyza huidobrensis populations and the Indonesian parasitoids Hemiptarsenus varicornis, Opius sp., and Gronotoma micromorpha, as well as the Australian parasitoids Hemiptarsenus varicornis and Diglyphus isaea. J. Econ. Entomol. 97: 1191-1197.

Quicke D.L.J. 1997: Parasitic Wasps. Chapman \& Hall, London, $470 \mathrm{pp}$.

Rauf A., Shepard B.M. \& Johnson M.W. 2000: Leafminers in vegetables, ornamental plants and weeds in Indonesia: surveys of host crops, species composition and parasitoids. Int. J. Pest Manag. 46: 257-266.

Roitberg B.D., Boivin G. \& Vet L.E.M. 2001: Fitness, parasitoids, and biological control: an opinion. Can. Entomol. 133: 429-438.

RosenHeIM J.A. \& Rosen D. 1991: Foraging and oviposition decisions in the parasitoid Aphytis lingnanensis: distinguishing the influences of egg load and experience. J. Anim. Ecol. 60: 873-893.

TOKUMARU S. \& ABE Y. 2003: Effects of temperature and photoperiod on development and reproductive potential of Liriomyza sativae, L. trifolii, and L. bryoniae (Diptera: Agromyzidae). Jpn. J. Appl. Entomol. Zool. 47: 143-152 [in Japanese with English abstr].

Vet L.E.M., Datema A., Janssen A. \& Snellen H. 1994: Clutch size in a larval-pupal endoparasitoid: consequences for fitness. J. Anim. Ecol. 63: 807-815.

Vinson S.B. 1976: Host selection by insect parasitoids. Annu. Rev. Entomol. 21: 109-133.

VINSON S.B. 1998: The general host selection behavior of parasitoid Hymenoptera and a comparison of initial strategies utilized by larvaphagous and oophagous species. Biol. Contr. 11: 79-96.

Vinson S.B. \& Iwantsch G.F. 1980: Host suitability for insect parasitoids. Annu. Rev. Entomol. 25: 397-419.

VISSER M.E. 1994: The importance of being large: the relationship between size and fitness in females of the parasitoid Aphaereta minuta (Hymenoptera: Braconidae). J. Anim. Ecol. 63: 963-978.

West S.A., Flangan K.W. \& Godfray H.C.J. 1996: The relationship between parasitoid size and fitness in the field, a study of Achrysocharoides zwoelferi (Hymenoptera: Eulophidae). J. Anim. Ecol. 65: 631-639.

Wishart G. \& Monteith E. 1954: Trybliographa rapae (Westw.) (Hymenoptera: Cynipidae), a parasite of Hylemya spp. (Diptera: Anthomyiidae). Can. Entomol. 86: 145-154.

Yоsнiмото C.M. 1963: Synopsis of Polynesian Cynipoidea (Hymenoptera: Eucoilidae). Pacif. Ins. 5: 433-443.

Received April 23, 2009; revised and accepted June 6, 2009 